\title{
Analisis Laju Infiltrasi Dengan Metode Penggenangan (Fooding) dan Karakteristik Tanah di Kabupaten Sampang, Madura
}

\author{
Qistan Maraghi Bagaskoro $^{1 *}$, Sri Wahyuni ${ }^{1}$, Ussy Andawayanti ${ }^{1}$ \\ ${ }^{1}$ Jurusan Teknik Pengairan, Fakultas Teknik, Universitas Brawijaya, \\ Jalan MT. Haryono No. 167, Malang, 65145, INDONESIA \\ *Korespondensi Email: qistanbagas35@gmail.com
}

\begin{abstract}
Rapid economic growth will lead to changes in land use and land cover in infrastructure development areas. As a result, it can increase the volume of rainwater into surface runoff that is not infiltrated into the soil. This study was conducted to analyze infiltration rate with a calculation of Horton Model, Holtan Model, and Phillip Model and to know the inundation that occurred and know the characteristics of the soil. This study was conducted at 10 review points with 10 different villages in Sampang Regency. At each point, infiltration rate readings using Turf-Tech Infiltrometer tools and soil sampling are about 5-10 meters from the infiltration reading point. Soil characteristics testing is carried out in soil and groundwater laboratory (Irrigation Technique). Rainfall data used in this study came from Sampang Rain Station, Omben Rain Station, Robatal Rain Station, Kedundung Rain Station, and Karangpenang Rain Station. From the results of the analysis, Horton Model is considered more suitable in this study in terms of ease in the calculation process and is considered appropriately applied based on the comparison of the field infiltration rate curve. 6 out of 10 review points occur inundation. Soil characteristic results have clay type at 2 points, clay dusty 2 point and dusty clay at 6 points
\end{abstract}

Keywords: Inundation, Infiltration rate, Rainfall, Soil Characteristic

Abstrak: Pertumbuhan ekonomi yang sangat pesat akan menyebabkan kepada perubahan tata guna lahan serta tutupan lahan pada area pembangunan infrastruktur. Akibatnya dapat menigkatnya volume air hujan menjadi aliran permukaan (surface run off) yang tidak terinfiltrasi ke dalam tanah. Penelitian ini dilaksanakan untuk menganalisis laju infiltrasi dengan perhitungan Model Horton, Model Holtan dan Model Phillip serta mengetahui genangan yang terjadi dan mengetahui karakteristik tanah. Kajian ini dilakukan pada 10 titik tinjau dengan 10 desa berbeda di Kabupaten Sampang. Pada setiap titik dilakukan pembacaan laju infiltrasi menggunakan alat Turf-Tech Infiltrometer dan pengambilan sampel tanah berjarak sekitar 5-10 meter dari titik pembacaan infiltrasi. Pengujian karakteristik tanah dilakukan di Laboraturium Tanah dan Air Tanah (Teknik Pengairan). Data curah hujan yang digunakan pada penelitian ini berasal dari Penakar hujan Sampang, Penakar Hujan Omben, Penakar Hujan Robatal, Penakar hujan Kedundung dan Penakar Hujan Karangpenang. Dari hasil analisis, Model Horton dianggap lebih cocok pada 
penelitian ini dari segi kemudahan dalam proses perhitungan serta dianggap tepat diterapkan berdasarkan dari perbandingan kurva laju infiltrasi lapangan. 6 dari 10 titik tinjau terjadi genangan. Hasil karakteristik tanah memiliki jenis tanah lempung pada 2 titik, lempung liat berdebu 2 titik dan lempung berdebu pada 6 titik

Kata Kunci: Genangan, Hujan, Karakteristik tanah, Laju infiltrasi

\section{Pendahuluan}

Pertumbuhan penduduk yang sangat cepat dapat memberikan dampak pada pembangunan infrastruktur untuk memenuhi segala kebutuhan masyarakat itu sendiri. Infrastruktur yang dibangun dengan skala yang lebih besar dan dilakukan dengan cepat bisa menyebabkan peningkatan volume air hujan yang melimpas menjadi aliran permukaan (suface run off) yang tidak terinfiltrasi secara maksimal kedalam tanah.

Dalam infiltasi dikenal dua istilah yaiu kapasitas infiltrasi dan laju infiltrasi.yang dinyatakan dalam $\mathrm{mm} / \mathrm{jam}$. Kapasitas infilltrasi adalah laju infiltrasi maksimum untuk suatu jenis tanah tertentu. Sedangkan laju infiltrasi adalah kecepatan infiltrasi yang nilainya tergantu pada kondisi tanah dan intensitas hujan [1].

Laju infiltrasi sangat dipengaruhi oleh nilai intensitas hujan. Nilai laju infiltrasi dapat kurang dari atau sama dengan kapasitas infiltrasi. Jika intensitas hujan kurang dari kapasitas infiltrasi maka laju infiltrasi yang terjadi akan kurang dari kapasitas infiltrasi dan dapat sama dengan nilai intensitas hujan itu sendiri. Dan, jika intensitas hujan lebih dari kapasitas infiltrasi maka laju infiltrasi akan sama dengan kapasitas infiltrasi [2].

Laju infiltrasi yang rendah di suatu daerah dimana di daerah tersebut mengalami kemarau panjang, sangat diperlukannya upaya konservasi pada sumber daya air di daerah tersebut. Memiliki lahan luas yang belum dimanfaatkan secara maksimal seharusnya memiliki laju infiltrasi bersifat tinggi yang berguna untuk menyimpan cadangan air tanah. Langkah yang tepat untuk dilaksanakan adalah penelitian infiltrasi dan limpasan di kawasan tersebut.

Permasalahan utama khususnya di Kabupaten Sampang adalah banjir dan kekeringan. Laju infiltrasi yang dikategorikan rendah ditambah dengan suhu yang tergolong panas di beberapa daerah Kabupaten Sampang sangat memperparah permasalahan yang sering timbul setiap tahunnya. Faktor lain yang bisa menjadi penunjang permasalahan ini pun adalah jenis tanah pada daerah tersebut. Pada saat pengambilan sampel sekaligus mengamati tanah di titik tersebut melalui cara penetapan kasar di lapangan, kesimpulan awal bahwa jenis tanah di daerah titik sampel adalah tanah lempung berpasir ang mempunyai sifat sangat mudah menyerap air dan cepat sekali menjadi jenuh sehingga banyak terjadi limpasan pada wilayah tersebut. Akan tetapi pada musim kemarau dengan suhu yang terik tanah ini menjadi keras dan membatu. Tidak jarang pada saat pengambilan sampel tanah pada titik lokasi harus diulang karena sifat tersebut.

Penelitian yang berkaitan tentang laju infiltrasi sangatlah penting dalam memprediksi besaran waktu dimana sifat tanah pada lokasi penelitian yang bermula bersifat tak jenuh air (permeable) menjadi jenuh akan air (impermeable). Dalam menunjang pada penelitian yang berkaitan tentang laju infiltrasi, penelitian tentang karakteristik tanah di titik lokasi juga diperlukan karena bertujuan mengetahui lebih dalam pengaruh terhadap waktu terjadinya genangan air.

Tujuan penelitian ini mengetahui karakteristik tanah pada titik lokasi dengan parameter kadar air, jenis gradasi agregat dan berat jenis butiran tanah. Lalu mengetahui laju infiltrasi yang terjadi di Kabupaten Sampang dengan metode penggenangan (flooding) terhadap tanah yang tidak jenuh (permeable) menggunakan Model Horton, Model Holtan, dan Model Phillip dan juga mengetahui sifatsifat genangan dengan parameter tinggi genangan terjadi dan lama terjadinya genangan di titik lokasi pada beberapa desa sampang, Kabupaten Madura. 
Adapun penelitian terdahulu yang emngambil tema tentang laju infiltrasi sebagai referensi. Berikut adalah daftar peneliti terdahulu yang telah melaksanakan penelitian yangbertemakan sama, yaitu :

1. Isnaini, Rika. 2013. Kajian Laju Infiltrasi pada Berbagai Penggunaan Lahan di Desa Sempajaya Kecamatan Berastagi Kabupaten Karo. Skripsi. Medan. Universitas Sumatera Utara

2. Qomari, Basri. 2017. Analisis Karakteristik Genangan Terhadap Kejadian Hujan dan Sifat Fisik Tanah di Universitas Brawijaya. Skripsi. Malang. Universitas Brawijaya

3. Renhardika, Ryan. Analaisa Penentuan Laju Infiltrasi pada Tanah dengan Variasi Kepadatan. Skripsi. Malang. Universitas Brawijaya

4. Wulan Ayu, Ieke. Sugeng Prijono. Soemarno. 2013. Assessment of Infiltration Rate under Different Drylands Types in Unter-Iwes Subdistrict Sumbawa Besar, Indonesia . 3(10):71-76

5. A.Akintoye,Oluyeni. Samuel U. Ukata. dan Henry I. Esomonyo. 2012. The Effects Of Landuse on the Infiltration Capacity of Coastal Plan Soil of Calabar Nigeria. 2(2): 80-84

6. Chandrasasi, Dian. Wahyuni, Sri. Timur, Elang. 2020. Study Determination Of Infiltration Rate In Permeable Soils With Flooding Method - Turf Tech Infilrometer In Universitas Brawijaya Campus II - Dieng $020036: 1-8$

\section{Bahan dan Metode}

\subsection{Bahan}

Pengambilan sampel nilai laju infiltrasi menurut SNI 7752:2012 tahun 2012 [3] Penelitian ini dilakukan pada 10 titik pemukiman di 10 desa berbeda di Kabupaten Sampang, Madura. Hampir pada seluruh titik lokasi penelitian banyak didominasi oleh tutupan lahan alami berupa semak belukar, pepohonan yang lebat. Adapun tutupan lahan yang artificial berupa perumahan penduduk dan jalan untuk penduduk di sekitar.

Berikut daftar desa yang menjadi lokasi atau titik peneltian, yaitu :

Tabel 1. Daftar Nama Desa dan Titik Koordinat Lokasi Penelitian

\begin{tabular}{|c|c|c|}
\hline No & Titik Koordinat & Nama Desa \\
\hline 1 & 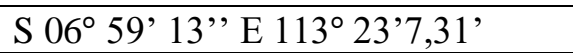 & Karang Penang Oloh \\
\hline 2 & S $07^{\circ} 00^{\prime} 44,49^{\prime \prime}$ E $113^{\circ} 19^{\prime} 29,13^{\prime \prime}$ & Lepelle \\
\hline 3 & S $07^{\circ} 01^{\prime} 04,33^{\prime \prime}$ E $113^{\circ} 18^{\prime} 27,299^{\prime \prime}$ & Robatal \\
\hline 4 & S $07^{\circ} 08^{\prime} 02,94^{\prime \prime}$ E $113^{\circ} 17^{\prime} 46,55^{\prime \prime}$ & Napo Dayah \\
\hline 5 & S 07० 04' 36,93"' E 113 19'14,98", & Pandan \\
\hline 6 & S $07^{\circ} 08^{\prime} 59,56^{\prime \prime}$ E $113^{\circ} 14^{\prime} 15,80^{\prime \prime}$ & Kamuning \\
\hline 7 & S $07^{\circ} 04^{\prime} 56,23^{\prime \prime}$ E $113^{\circ} 14^{\prime} 46,57^{\prime \prime}$ & Kedundung \\
\hline 8 & 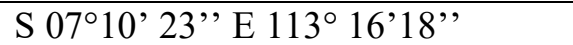 & Panggung \\
\hline 9 & S $07^{\circ} 2^{\prime} 53,88^{\prime \prime}$ E $113^{\circ} 21^{\prime} 23,09^{\prime \prime}$ & Blu'uran \\
\hline 10 & S $07^{\circ} 02^{\prime} 47,54^{\prime \prime}$ E $113^{\circ} 16^{\prime} 50,89^{\prime \prime}$ & Gunungeleh \\
\hline
\end{tabular}

Sumber: Hasil Penelitian

Data yang diperoleh pada penelitian ini ada dua tipe data, yaitu data primer dan sekunder untuk analasis. Data primer yang didapatkan pada penelitian ini adalah data yang diperoleh dari hasil dari lapangan, yaitu :

- Data laju Infiltrasi dari 10 titik lokasi menggunakan bantuan alat Turf-Tec Infiltrometer yang terdapat waktu antara 0 menit sampai 100 menit.

- Data karakterisik tanah dengan parameter kadar air, jenis gradasi agregat dan berat jenis butiran tanah yang didapatkan dari pengujian di laboraturium tanah dan air tanah (Teknik Pengairan) dan juga sampel tanah yang didapatkan dari pengambilan langsung di lapangan. 


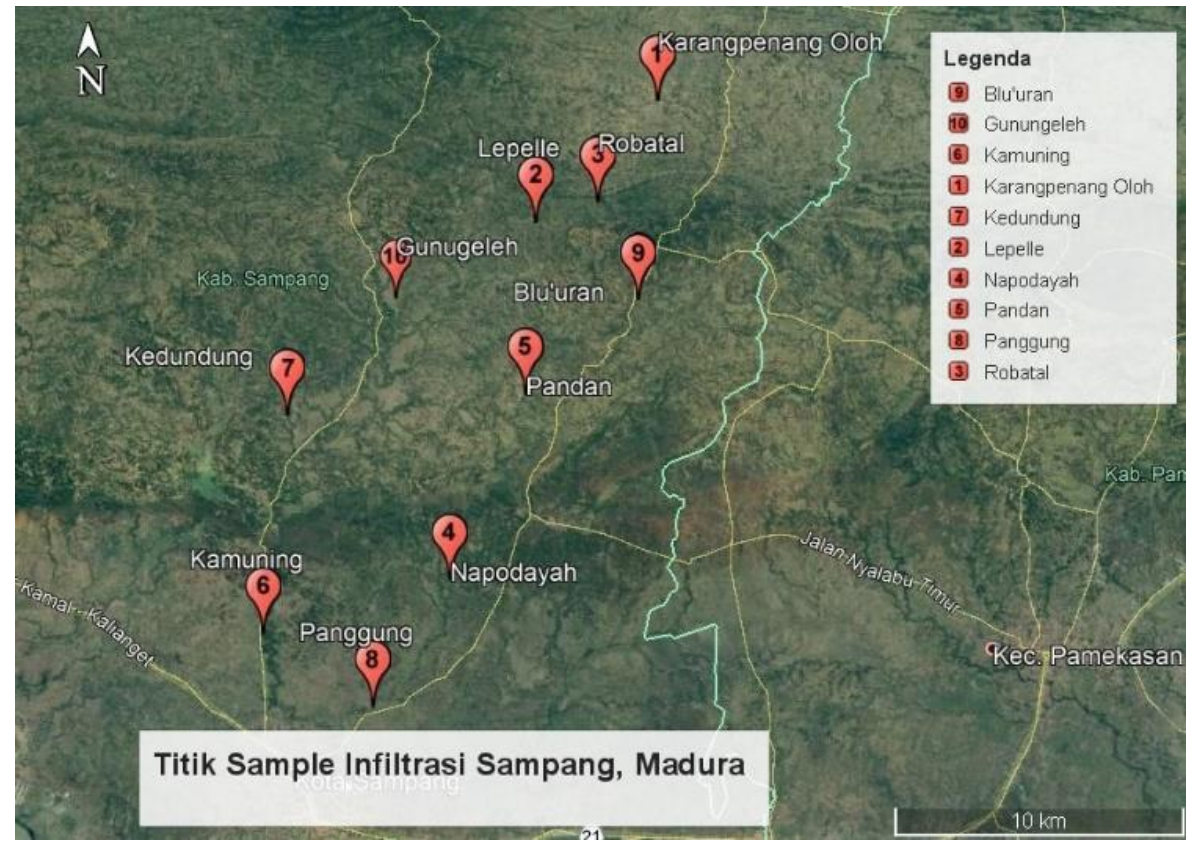

Gambar 1. Peta Nama Desa Sampang, Kabupaten Madura

Untuk data sekunder di penelitian ini adalah data yang dikumpulkan dari instansi terkait, yaitu :

- Data Curah Hujan harian yang didapatkan dari Dinas Pengairan Kabupaten Sampang

- Data curah hujan didapatkan dari 5 (lima) stasiun hujan yaitu Stasiun curah hujan kecamatan Sampang, Stasiun curah hujan Kecamatan Omben, Stasiun Curah Hujan Kecamatan Robatal, Stasiun Curah Hujan Kecamatan Kedundung, Curah Hujan Kecamatan Karangpenang

- Rentang waktu pengambilan data curah hujan harian dimulai dari tahun 1999 hingga 2018 (20 tahun).

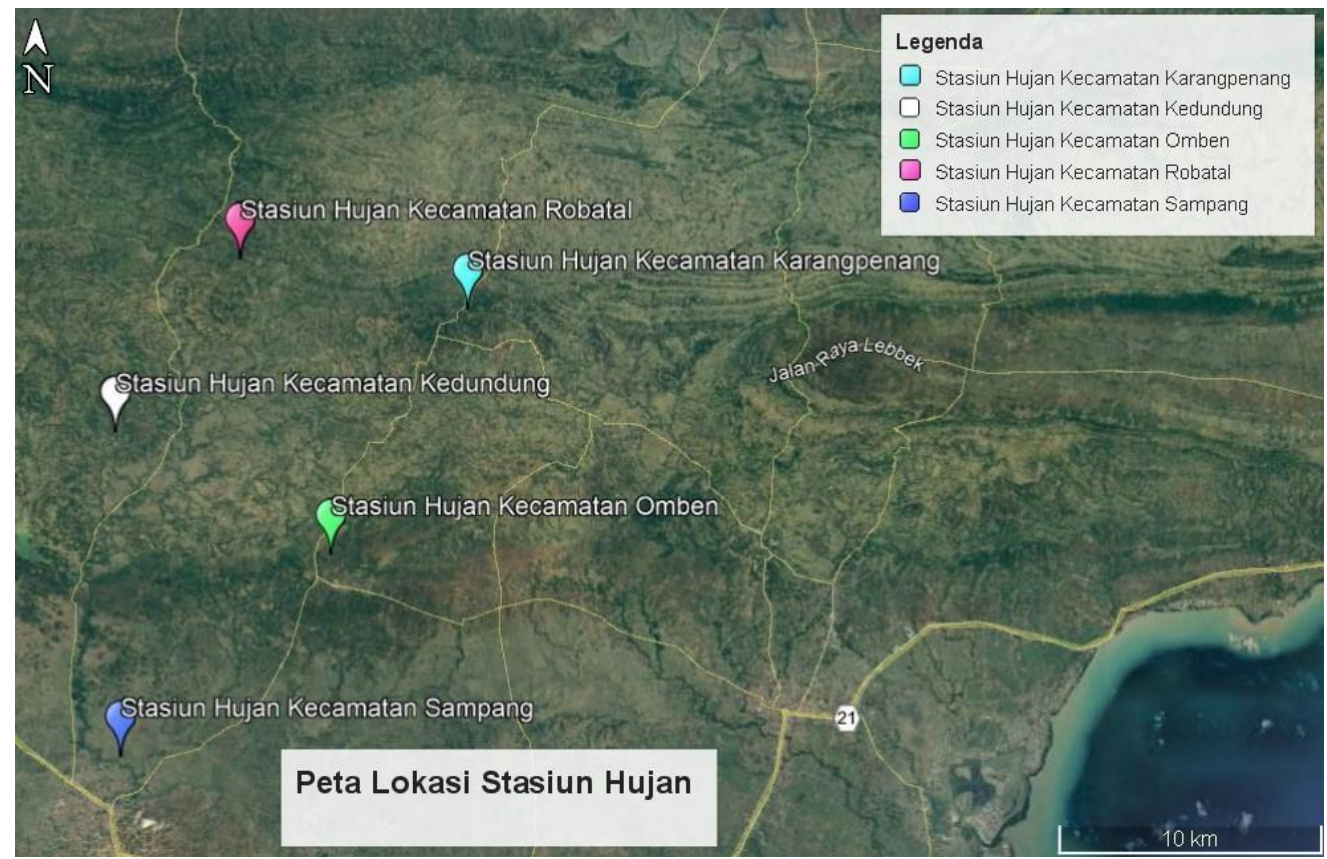

Gambar 2. Lokasi Stasiun Hujan 


\subsection{Metode}

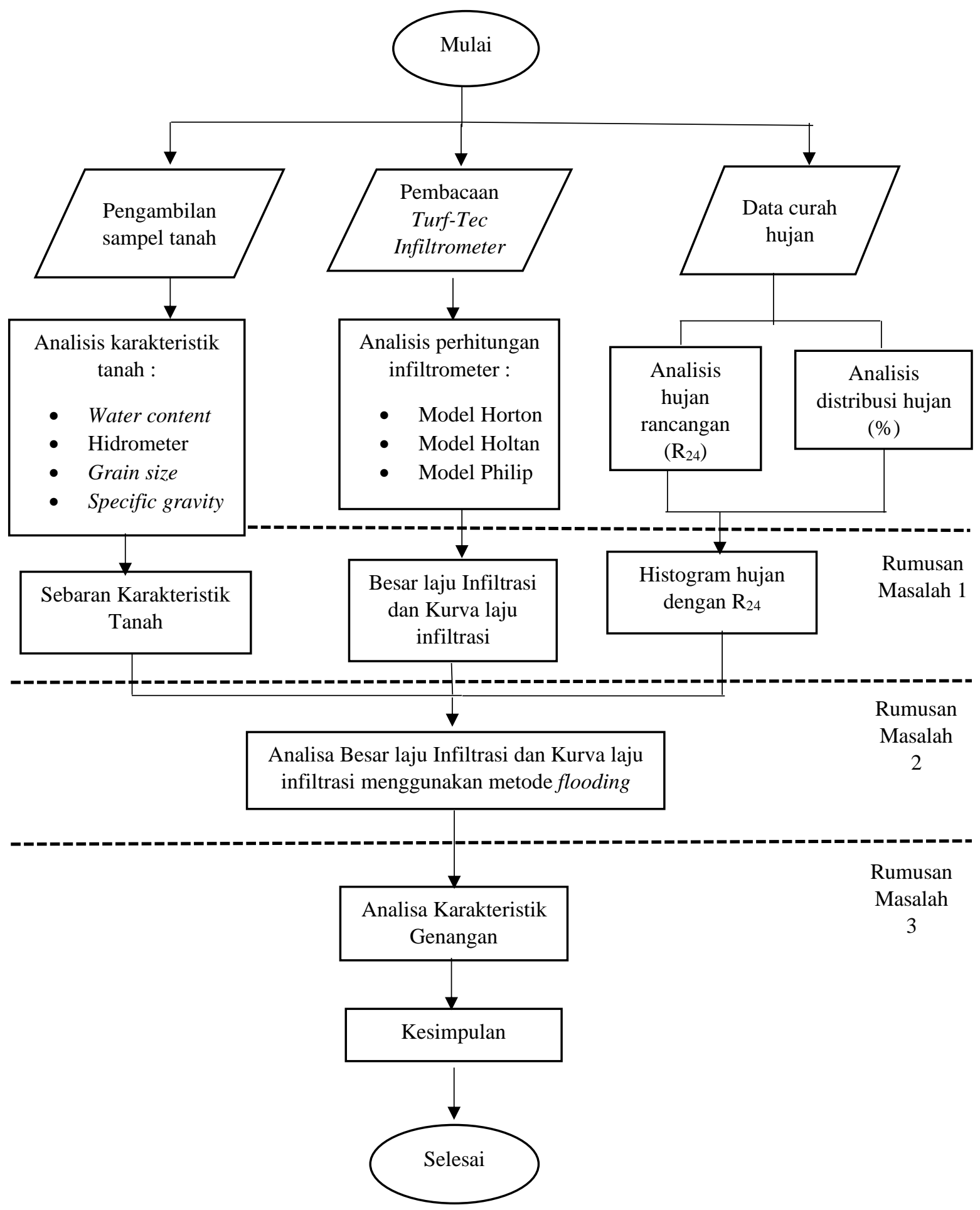

Gambar 3. Bagan Alir Pengerjaan Studi

Sumber: Hasil Penggambaran

Alur pengerjaan skripsi yang tergambar kan pada bagan alir pengerjaan studi pada gambar 3 diatas, data yang didapatkan dari data primer dan data sekunder. Data primer yang didapatkan pada kajian ini diambil dari pengambilan proses pembacaan laju infiltrasi menggunakan Turf-Tec Infiltrometer untuk mendapatkan nilai laju infiltrasi dan pengambilan sampel tanah di lapangan lalu dilakukan pengujian karakteristik tanah di Laboraturium Air Tanah dan Tanah lalu melakukan analisis sebaran karakteristik 
tanah. Data sekunder yang didapatkan pada penelitian ini adalah data curah hujan yaitu data curah hujan stasiun sampang, stasiun omben, stasiun robatal, stasiun kedundung dan stasiun karangpenang yang didapatkan dari Dinas Pengairan Kabupaten Sampang. Nilai laju infiltrasi yang didapatkan akan dianalisa menggunakan Model Horton, Model Phillip dan Model Holtan. Hasil pengujian sampel tanah akan didapatkan berupa parameter Water Content, Specific Grafity, Grain Size dan Hidrometer. Untuk analisis hidrologi data curah hujan akan didapatkan hasil histogram hujan jam-jaman dan untuk karakteristik genangan yang didapatkan dengan cara menggambungkan grafik pembacaan laju infiltrasi lapangan dan histogram hujan jam-jaman.

\section{Hasil dan Pembahasan}

\subsection{Sebaran Karakteristik Tanah}

Setelah melakukan pengujian berdasarkan SNI No 1965 Tahun 2008 [4] dan SNI No. 3423 Tahun 2008 [5] Berikut sebaran karakteristik tanah yang sudah melalui pengujian dan analisis dalam tabel 2 dan tabel 3.

Tabel 2. Hasil Klasifikasi Infiltrasi dan Kadari Air Sebaran Karakteristik Tanah

\begin{tabular}{ccccc}
\hline \hline \multirow{2}{*}{ No } & Lokasi /No. Titik & $\begin{array}{c}\text { Laju Infiltrasi } \\
\text { Konstan }\end{array}$ & Klasifikasi & \multirow{2}{*}{ Kadar Air $(w)(\%)$} \\
\cline { 2 - 4 } & & $(f c)(\mathrm{mm} / \mathrm{menit})$ & Laju Infiltrasi & \\
\hline 1 & Karangpenang & 1,5 & Lambat & 6,734 \\
\hline 2 & Lepelle & 3 & Lambat & 3,152 \\
\hline 3 & Robatal & 0,5 & Sangat Lambat & 1,5 \\
\hline 4 & Napodaya & 1 & Lambat & 11,015 \\
\hline 5 & Pandan & 0,6 & Sangat Lambat & 1,333 \\
\hline 6 & Kamuning & 5,6 & Agak Lambat & 15,651 \\
\hline 7 & Kedundung & 10,3 & Agak Lambat & 3,214 \\
\hline 8 & Panggung & 9 & Agak Lambat & 3,907 \\
\hline 9 & Blu'uram & 0,1 & Sangat Lambat & 2,34 \\
\hline 10 & Gunungeleh & 0,1 & Sangat Lambat & 4,268 \\
\hline & Rerata & \multicolumn{3}{c}{3,170} \\
\hline \hline
\end{tabular}

Tabel 3. Hasil Sebaran Karakteristik Tanah

\begin{tabular}{|c|c|c|c|c|c|c|}
\hline \multirow{2}{*}{ No } & \multirow{2}{*}{ Lokasi /No. Titik } & \multirow{2}{*}{$\begin{array}{c}\text { Berat Jenis } \\
\text { Tanah }\end{array}$} & \multicolumn{3}{|c|}{ Hasil Gradasi Butir } & \multirow{2}{*}{ Jenis Tanah } \\
\hline & & & $\begin{array}{c}\text { Sand } \\
(\%)\end{array}$ & $\begin{array}{l}\text { Silt } \\
(\%)\end{array}$ & $\begin{array}{c}\text { Clay } \\
(\%)\end{array}$ & \\
\hline 1 & Karangpenang & 2,478 & 13,55 & 65,867 & 20,583 & Lempung berdebu \\
\hline 2 & Lepelle & 2,197 & 7,894 & 66,986 & 25,12 & Lempung Liat berdebu \\
\hline 3 & Robatal & 2,083 & 10,71 & 61,35 & 27,94 & Lempung Liat berdebu \\
\hline 4 & Napodaya & 2,744 & 30,588 & 50,131 & 19,281 & Lempung \\
\hline 5 & Pandan & 2,462 & 43,546 & 35,22 & 21,232 & Lempung \\
\hline 6 & Kamuning & 2,273 & 13,072 & 68,031 & 18,897 & Lempung berdebu \\
\hline 7 & Kedundung & 2,418 & 14,25 & 67,109 & 18,641 & Lempung berdebu \\
\hline 8 & Panggung & 2,462 & 20,954 & 59,285 & 19,762 & Lempung berdebu \\
\hline 9 & Blu'uram & 2,35 & 23,656 & 58,065 & 18,28 & Lempung berdebu \\
\hline \multirow[t]{2}{*}{10} & Gunungeleh & 2,297 & 11,748 & 63,037 & 25,215 & Lempung berdebu \\
\hline & Rerata & 2,376 & 18,997 & 59,508 & 21,495 & \\
\hline
\end{tabular}


Berdasarkan hasil sebaran karakteristik tanah di Kabupaten Sampang, madura yang sudah melalui pengujian dan analisis pada tabel 2 dan tabel 3, terlihat analisis Water Content bahwa pada titik kamuning memeiliki kadar air yang lebih besar dari titik lainnya hanya sebesar $15,651 \%$ dan titik pandan menjadi yang terkecil dengan 1,330\%., lalu pada hasil pengujian dan analisis Specific Gravity diatas, menunjukkan bahwa titik napodaya paling tertinggi dengan 2,744 dan titik robatal paling terkecil dari titik lainnya dengan 2,083. Rerata dari hasil analisis 10 titik sampel sebesar 2,376.

Lalu pada Pengujian dan analisis Grain Size dan hidrometer yang sebetulnya adalah percobaan yang berkelanjutan untuk mengetahui jenis tanah yang di uji. Hasil dari pengujian dan analisis Grain Size masih digunakan dan dilanjutkan untuk analisis hidrometer, yang membedakan dari dua pengujian ini adalah jika di pengujian Grain Size dangan cara mengayak tanah menggunakan saringan bernomor dari $1 / 2$ sampai nomor 200 tetapi untuk pengujian hidrometer dengan menggunakan metode hidrometer yang prinsip pengujian ini adalah sedimentasi (pengendapan). Terlihat pada tabel diatas bahwa jenis tanah yang terdapat pada 10 titik sampel uji didominasi tanah lempung berdebu, lempung liat berdebu dan lempung.

\subsection{Model Infiltrasi}

Pada Model infilitrasi yang digunakan pada penelitian ini adala Model Horton, Model Phillip dan Model Holtan. Perhitungan laju infiltrasi menggunakan metode Horton (1933, 1939). Horton mengamati bahwa infiltrasi berawal dari suatu nilai baku fo dan secara eksponen menurun sampai pada kondisi konstan fc. Salah satu persamaan infiltrasi paling awal yang dikembangkan oleh Horton adalah:dimana $\mathrm{k}$ adalah pengurangan konstan terhadap dimensi [ $\mathrm{T}-1]$. fo adalah kapasitas infiltrasi awal.Sedangkan fc adalah kapasitas infiltrasi konstan yang tergantung pada tipe tanah. Parameter fo dan fc didapat dari pengukuran di lapangan menggunakan alat double ring infiltrometer. Parameter fo dan fc adalah fungsi jenis tanah dan tutupan. Untuk tanah berpasir atau berkerikil nilai tersebut tinggi, sedang tanah berlempung yang gundul nilainya kecil, dan apabila permukaan tanah ada rumput nilainya bertambah. [6]

Dalam infiltrasi model phillip, Philip (1957) memiliki anggapan jika profil lengas tanah mendekati suatu bentuk yang konstan dan bergerak menuju ke bawah dengan kecepatan yang konstan setelah melewati waktu yang panjang [hadisusanto] pada permusan model Phillip, Phillip mendefinisikan sorptivitas sebagai kuantitas yang terukur yang menggambarkan kapasitas media berpori dan pelepasan cairan. White dan perroux (1987) menyebutkan bahwa sorptivits sebagai properti atau variabel integral tanah difusi hidrolik. Sorptivitas akan konstan jika kandungan air di ujung inflow pun konstan[7]

Holtan (1961) menggambarkan persamaan empiris berdasarkan konsep penyimpanan. Persamaan ini dikembangkan di laboratorium hidrograf USDA dari Layanan Penelitian Agikultural untuk menyediakan sarana di mana infiltrasi dapat diperkirakan menggunakan informasi yang umumnya tersedia atau dapat dengan mudah diperoleh untuk tanah utama (Holtan,1967)Persamaannya adalah bahwa faktor-faktor dengan pengaruh terbesar atas tingkat infiltrasi adalah penyimpanan air tanah, porositas yang terhubung permukaan, dan efek jalur akar tanaman [8].

Berdasarkan gambar 4 yang menampilkan grafik hasil analisis model infiltrasi pada titik blu'uran menunjukkan bahwa jika dibandingkan dngan laju infiltrasi lapangan, pada model horton memang berbeda akan tetapi pada model ini sangat menekankan pada kualitas nilai laju infiltrasi dan waktu yang dibutuhkan pada lapangan. Lalu pada model phillip juga berbeda jika dibandingkan dengan grafik laju infiltrasi lapangan akan tetapi pada model ini sama sama membutuhkan nilai dan jumlah nilai laju infiltrasi per satu kali percobaan dan berapa waktu yang dibutuhkan. 


\section{Rekapitulasi Nilai Laju Infiltrasi Metode Penggenangan Titik Blu'uran}

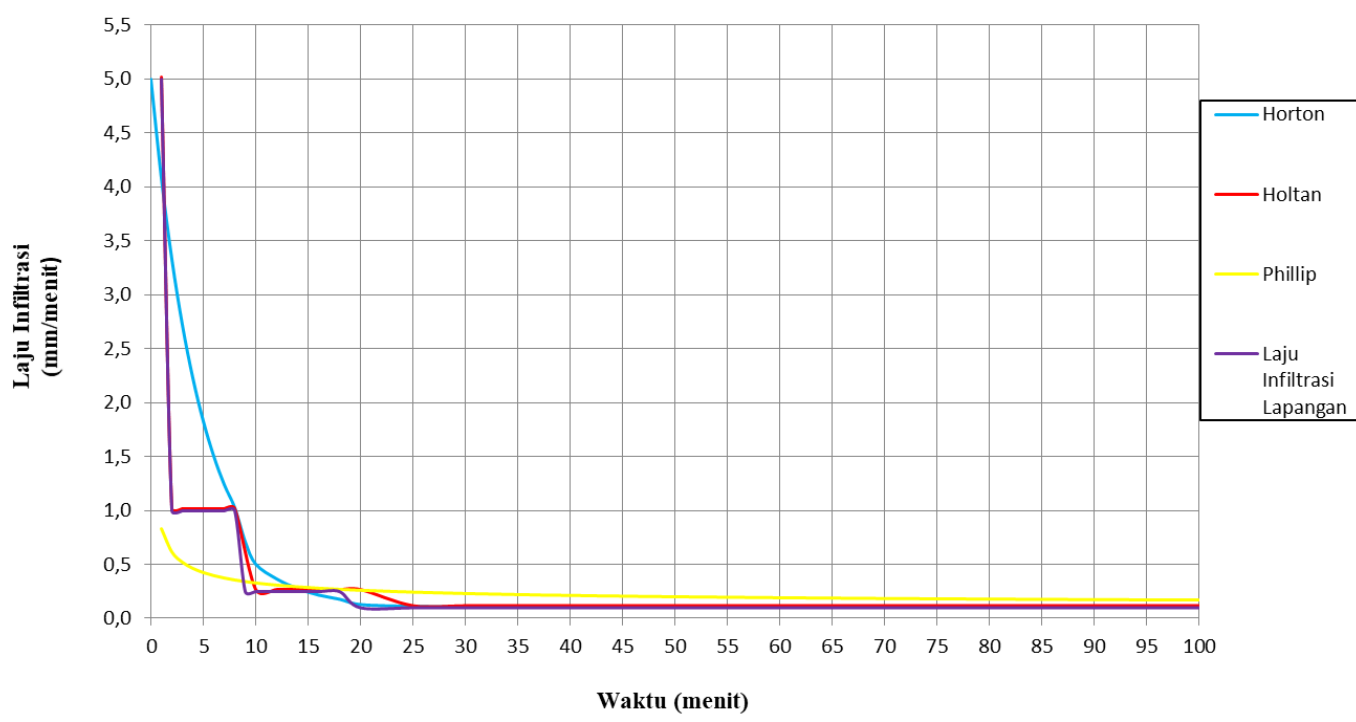

Gambar 4. Hasil Analisis Model Infiltrasi Titik Blu'uran

Pada model holtan berbeda dengan dua model yang sudah dijabarkan, karena pada model ini sangat mengandalkan nilai laju infiltrasi lapangan dan tutupan lahan pada titik sampel. Tutupan vegetasi lahan pada titik sampel menjadi variabel di dalam analasis ini, dikarenakan pada Model Horton dibutuhkan GI (Growth Index) atau koefisien tanaman, selain itu dibutuhkan variabel (a) yaitu klasifikasi kondisi lahan pada titik sampel, dan SA atau penyimpanan air di permukaan lahan melalui perhitungan yang membutuhkan analisa rata rata kadar air (Water Content) dengan kedalaman pembersihan dan perataan alat Turf-tec Infiltrometer. dan pada gambar diatas pun menunjukkan bahwa hasil pada model ini tidak terlalu jauh berbeda dengan nilai laju infiltrasi lapangan.

Pada penelitian ini Model Horton menjadi model yang paling cocok untuk digunakan, karena pada model ini dari segi perhitungan tidak ada unsur penambahan selain dari nilai laju infiltrasi dan waktu pengujian. Model perhitungan yang paling cocok hampir di semua kondisi tanah dalam analisis pembacaan laju infiltrasi adalah Model Horton[9] Model Horton lebih mementingkan pada ketelitian didalam pengamatan dari hasil pembacaan infiltrometer di lapangan yang ditinjau dan tanpa perlu ada pertambahan unsur lain didalam perhitungannya [10].

\subsection{Analisa Genangan}

Analisis genangan didapatkan dengan cara penggabungan kurva yaitu kurva pembacaan laju infiltrasi lapangan dengan histogram hujan, dimana akan didapatkan tinggi genangan yang terbentuk beserta lama genangan terjadi, selain itu bisa didalam perhitungan tabel, jika nilai laju infiltrasi lebih kecil dari intesitas hujan yang terjadi pada menit tertentu, maka bisa dikatakan pada menit tertentu tersebut terjadi adanya genangan dan berapa lama genannya.

Berikut contoh hasil analisis histogram hujan pada penakar hujan karangpenang dan hasil analisis genangan pada gambar 4 dan gambar 5 di salah satu titik sampel yaitu blu'uran yang dimana titik sampel ini sering terjadi genangan dalam penelitian ini.

Berdasarkan gambar 5 hasil analisis grafik histogram hujan jam jaman pada stasiun penakar hujan karangpenang dengan kala ulang 2 tahun, 5 tahun, 10 tahun dan 25 tahun menunjukkan bahwa pada stasiun tersbut pada kala ulang 25 tahun sebesar $3,438 \mathrm{~mm} / \mathrm{menit}$ menjadi yang paling terbesar jika dibandingkan dengan histogram penakar hujan lainnya yaitu penakar hujan sampang, robatal, omben dan kedundung. 


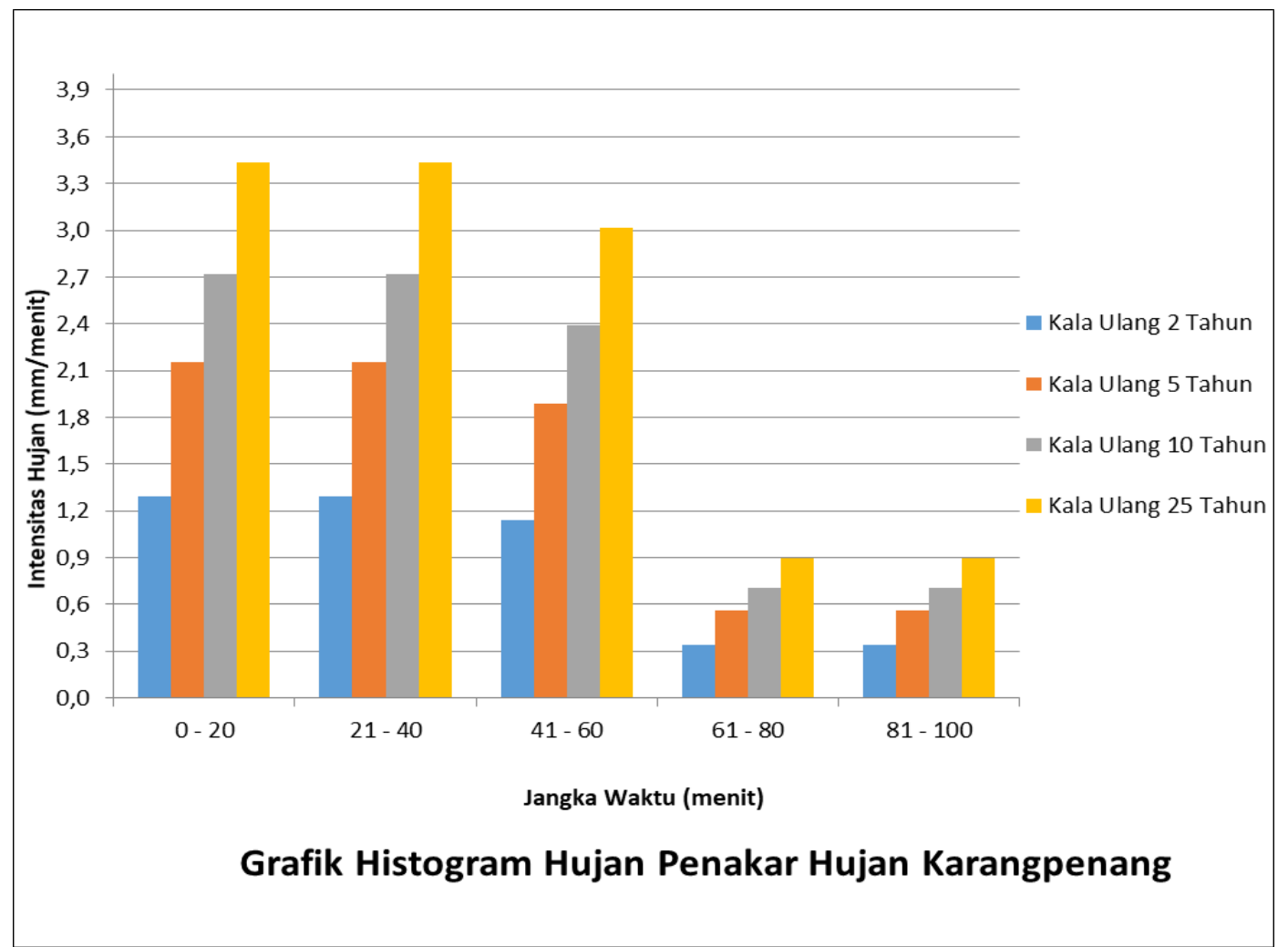

Gambar 5. Grafik Histogram Hujan Penakar Hujan Karangpenang

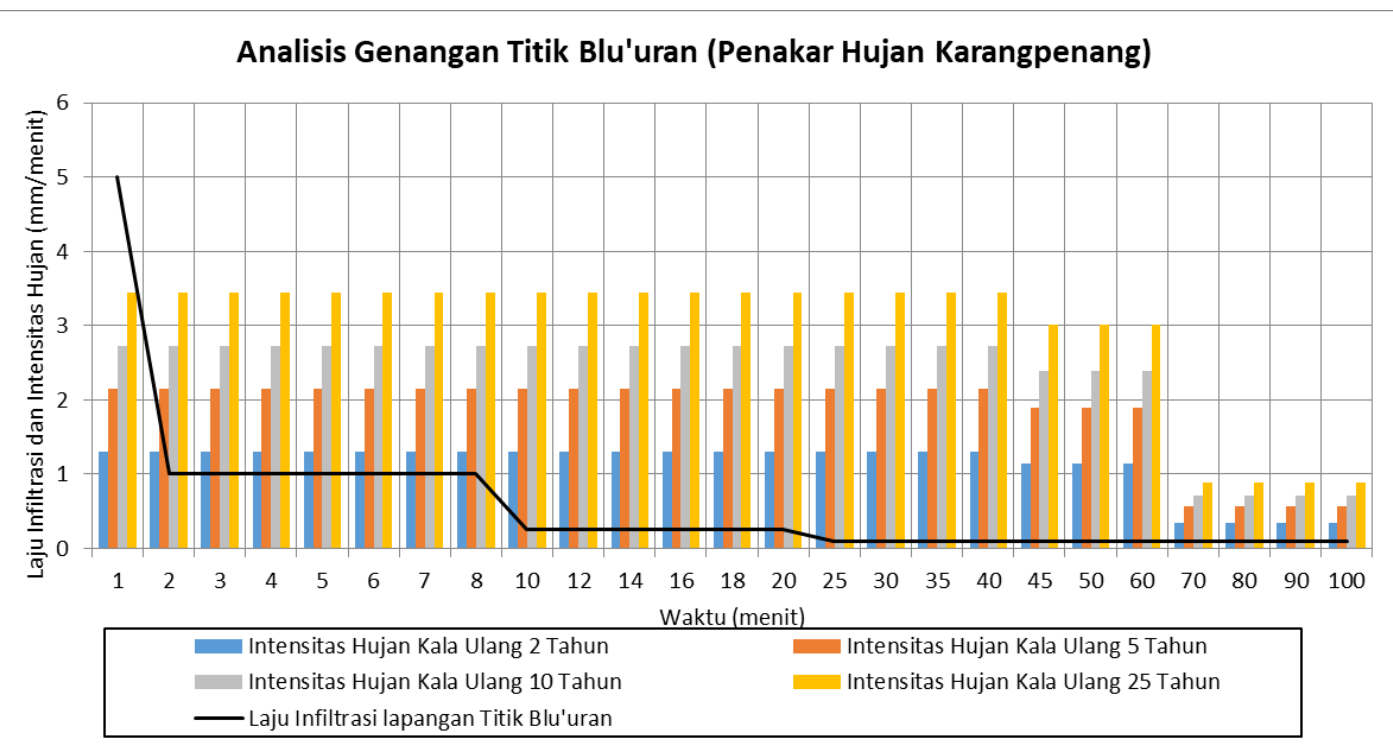

Gambar 6. Grafik Analisis Genangan Titik Blu'uran

Pada gambar 6 hasil analisis genangan pada titik blu'uran terlihat bahwa pada titik ini sudah terjadi genangan dari menit ke-2 sampai menit ke-100. Ini terjadi karena pada titik ini nilai laju infiltrasi lapangan termasuk kecil jika dibandingkan dengan ke 9 titik lainnya. Ditambah dengan hasil analisis histogram hujan stasiun penakar karangpenang yang terbilang tinggi juga menjadi faktor terjadinya genangan di titik tersebut. Berikut tabel 4 yang merekapitulasi titik sampel mana saja terjadinya genangan pada penakar hujan karangpenang. 
Tabel 14. Hasil Analisis Genangan Penakar Hujan Karangpenang

\begin{tabular}{ccccc}
\hline \hline & \multicolumn{4}{c}{ Kejadian Genangan (Penakar Hujan Karangpenang) } \\
\cline { 2 - 5 } Titik Tinjau & Kala Ulang & Kala Ulang & Kala Ulang & Kala Ulang \\
\cline { 2 - 5 } & 2 Tahun & 5 Tahun & 10 Tahun & 25 Tahun \\
\hline Karangpenang & - & Terjadi & Terjadi & Terjadi \\
\hline Lepelle & - & - & - & Terjadi \\
\hline Robatal & Terjadi & Terjadi & Terjadi & Terjadi \\
\hline Napodaya & Terjadi & Terjadi & Terjadi & Terjadi \\
\hline Pandan & Terjadi & Terjadi & Terjadi & Terjadi \\
\hline Kamuning & - & - & - & - \\
\hline Kedundung & - & - & - & - \\
\hline Panggung & - & - & - & - \\
\hline Blu'uran & Terjadi & Terjadi & Terjadi & Terjadi \\
\hline Gunungeleh & Terjadi & Terjadi & Terjadi & Terjadi \\
\hline \hline
\end{tabular}

Sumber: Sumber Perhitungan

Berdasarkan tabel 4 tentang rekapitulasi hasil analisis genangan penakar hujan karangpenang, pada penakar hujan tersebut banyak terjadinya genangan karena terdapatnya genangan pada titik lepelle kala ulang 25 tahun. Ini sedikit berbeda pada penakar hujan lainnya yang sama sama terdapat 6 titik sampel terjadinya genangan dengan kala ulang yang sama. Pada ke 6 titik sampel tersebut yaitu titik karangpenang, robatal, napodaya, pandan, blu'uran dan gunungeleh kejadian genangan bermacam macam. sebagai contoh pada titik lokasi Robatal, Pandan, Blu'uran dan Gunungeleh genangan terjadi dimulai dari menit ke-2 sampai menit ke-60. Genangan yang terjadi pada titik karangpenang dan napodaya berkisar dari menit ke-25 sampai menit ke-60 dan pada titik lepelle yang hanya terjadi di stasiun karangpenang dengan kala ulang 25 tahun, terjadinya genangan berkisar dari menit ke-50 sampai menit ke-60.

\section{Kesimpulan dan Saran}

\subsection{Kesimpulan}

Berdasarkan dari hasil pengujian dan analisis data pada penelitian ini yang telah dilakukan maka bisa diambil kesimpulan sebagai berikut:

1. Sebaran karakteristik tanah pada 10 titik sampel pada Kabupaten Sampang, Madura dapat dijabarkan sebagai berikut:

- Berdasarkan sebaran gradasi agregat jenis tanah yang didapatkan adalah jenis lempung berdebu pada 6 desa yaitu Titik Karangpenang, Titik Kamuning, Titik Kedundung, Titik Panggung, Titik Blu'uran, Titik Gunungeleh. Pada Titik Napodaya dan Pandan berjenis tanah Lempung lalu pada Titik Lepelle dan Napodaya berjenis lempung liat berdebu

- Berdasarkan rerata diameter butir tanah, jenis tanah yang diperoleh adalah lanau

- Berdasarkan rerata berat jenis tanah, jenis tanah yang didapatkan adalah pasir

2. Dari analisis pembacaan laju infiltrasi dan perhitungan dengan Model Horton, Model Phillip dan Model Holtan, pada penelitian ini bisa disimpulkan bahw Model Horton sangat cocok digunakan karena pada model ini cocok di semua kondisi tanah dan model tersebut sangat mementingkan ketelitian data laju infiltrasi lapangan dan tanpa ada penambahan unsur lain.

3. Hasil dari analisis genangan yang dilakukan dalam penelitian ini menunjukkan bahwa dari 10 titik di 10 desa berbeda yang dijadikan sampel, 7 diantaranya terjadi genangan dengan lama waktu yang bervariasi juga kala ulang yg sama di semua penakar hujan. Hal ini juga menjadi gambaran bahwa di 10 desa tersebut daya serap tanah terhadap air sangatlah kecil sehingga ketika hujan terjadi dalam waktu yang singkat saja bisa terjadi genangan juga diperparah dengan suhu yang ekstrim 
pada daerah tersebut dan sebaran karakteristik tanah pun bisa sangat mempengaruhi keadaan tersebut.

4.2. Saran

Saran yang dibutuhkan untuk penyempurnaan penelitian selanjutnya antara lain:

1. Perbanyak titik sampel pembacaan dan pemngambilan sampel tanah untuk meningkatkan keakuratan dari hasil analisis.

2. Dalam pembacaan laju infiltrasi lapangan, sangat direkomendasikan jika pembacaan tersebut dilakukan dalam dua musim yang berbeda sehingga bisa mengetahui perbedaan hasil analisis dengan titik yang sama

\section{Daftar Pustaka}

[1] Triatmodjo, B. 2008. Hidrologi Terapan. Yogyakarta: Beta Offset.

[2] Soemarto, C. D. 1987. Hidrologi Teknik. Surabaya: Usaha Nasional

[3] Badan Standar Nasional Indonesia. 2008. SNI 7752:2012 (2012) Cara Uji Penentuan Tata Cara Pengukuran Laju Infiltrasi Tanah di Lapanga Menggunakan Infiltrometer Cincin Ganda

[4] Badan Standar Nasional Indonesia. 2008. SNI 03-1965-2008 Cara Uji Penentuan Kadar Air Untuk Tanah dan Batuan di Laboraturium

[5] Badan Standar Nasional Indonesia. 2008. SNI 03-3423-2008 Cara Uji Analisis Ukuran Butir Tanah.

[6] Juliastuti dan Andryan Suhendra. 2012. "Studi Kapasitas Infiltrasi Metode Horton Untuk Pemakaian Biopori Di Kampus Universitas Bina Nusantara Berdasarkan Debit Limpasan Permukaan”, Jurnal Teknik Sipil, Fakultas Teknik. Universitas Bina Nusantara. Vol(2).No.2

[7] Ellen R. Tuner. 2006. "Comparison Of Infiltration Equations And Their Field Validation With Rainfall Simulation', Department of Biological resources Engineering, Chapter (II)-31.

[8] Rawls, W. J., L. R. Ahuja, D. L. Brakensiek, A. Shirmohammadi. 1993 . "Infiltration and soil water movement". In Handbook of Hydrology. McGraw-Hill, Inc

[9] Jagdale Satyawan Dagadu, Nimbalkar P.T. 2012. 'Infiltration Studies Of Different Soils Under Different Soil Conditions And Comparison Of Infiltration Model With Field Data". International Journal Of Advanced Engineering technology. Vol (III) Issue (II) : 154-157

[10] Sonaje, N. P. 2013. "Modelling of Infiltration Process" - A Review. Indian Journal of Applied Research. III (9): 226 - 230. 